\title{
25 Research Soure \\ The Trend in Cesarean Myomectomies and The Risk of Obstetrical Complications in Korea
}

\section{Min Jeong Kim}

The Catholic University of Korea

\section{Kyungeun Lee}

The Catholic University of Korea

Jae Young Park

The Catholic University of Korea

Ji Hye Jo

The Catholic University of Korea

In Yang Park ( $D$ ooooobbbbb@catholic.ac.kr)

The Catholic University of Korea

\section{Research Article}

Keywords: Leiomyoma(S), Cesarean myomectomy, Cesarean section, Pregnancy outcome, Risk factors

Posted Date: November 2nd, 2021

DOI: https://doi.org/10.21203/rs.3.rs-1014208/v1

License: (c) (i) This work is licensed under a Creative Commons Attribution 4.0 International License. Read Full License 


\section{Abstract \\ Background}

To evaluate the pregnancy outcomes and the risk of adverse obstetrical outcomes from cesarean myomectomy (CM) compared to cesarean section (CS)-only and to investigate the trend of surgeons in choosing $\mathrm{CM}$.

\section{Methods}

A retrospective cohort study was done of all patients who underwent CS that was complicated with leiomyoma at two university hospitals from January 2010 to May 2020. All patients were categorized into the CM group or the CS-only group. We analyzed the demographic factors, obstetric factors, surgical outcomes, and possible risk factors for adverse outcomes between the two groups.

\section{Results}

A total of 438 women in the CS-only group and 341 women in the CM group were included. Women who underwent CS-only had significantly more history of a previous myomectomy and multiple leiomyomas compared to women who underwent $\mathrm{CM}$. The gestational days at delivery and the pregnancy complications were significantly higher in the CS group. The mean size of the leiomyomas was larger in the CM group than in the CS only group $(5.8 \pm 3.2 \mathrm{~cm}$ vs $5.2 \pm 3.1 \mathrm{~cm}, P=0.005)$. Operation time and history of previous CS and preterm labor were higher in the CM group. It seems that preterm labor and abnormal presentation were relatively higher in the CM group than in the CS group due to the presence of leiomyoma. There were no significant differences in the pre and postoperative hemoglobin levels. The size of the leiomyoma (odds ratio $[\mathrm{OR}]=1.162 ; 95 \%$ confidence interval [Cl]: $1.07-1.25 ; P<0.001$ ) and operation time $>60$ minutes $(\mathrm{OR}=2.461 ; 95 \% \mathrm{Cl}: 1.45-4.15)$ were significant independent predictors of adverse outcomes after $\mathrm{CM}$.

\section{Conclusions}

Cesarean myomectomy is a reliable and safe approach to prevent the need for another operation for remnant leiomyoma. In this study, surgeons seemed to perform CM when uterine leiomyomas were large, the subserosal type, or few in number. Standardized treatment guidelines for myomectomy during cesarean section in pregnant women with uterine fibroids should be established.

\section{Background}

Uterine leiomyomas are the most common benign tumor of female reproductive organs, with a prevalence of $20-25 \%$ [1]. In South Korea, the number of women who visited medical clinics due to 
uterine leiomyomas increased from 340,191 in 2016 to 514,260 in 2020 [2]. The prevalence of leiomyoma during pregnancy has been reported to be $2-5 \%$ according to several studies [3-5]. Most leiomyomas are asymptomatic during pregnancy. Abdominal pain, pelvic pressure, and vaginal bleeding may occur in symptomatic pregnant women. Various obstetric complications such as preterm delivery, miscarriage, intrauterine growth retardation (IUGR), and failure of vaginal delivery may also occur in pregnant women with leiomyomas [3].

Leiomyoma encountered during a cesarean section poses a therapeutic dilemma. Myomectomy is a safe surgical option in women who desire pregnancy. Although uterine rupture related to myomectomy is extremely rare, the relationship between myomectomy in pregnancy and outcomes are very important in the management of pregnant women by obstetricians.

Issues regarding myomectomy during a cesarean section remain controversial. Generally, cesarean myomectomy (CM) has been discouraged because of the risk of postpartum complications such as hemorrhage, fever, and il [6]. However, when myomectomy is done concurrently with a cesarean section (CS), the burden of an additional surgery under general anesthesia is reduced. In recent decades, increasing studies have shown the safety and feasibility of CM $[7,8]$.

The objective of our study was to evaluate the outcomes of CM versus CS alone in women with uterine leiomyomas and evaluate the risk factors for adverse outcomes in women undergoing $\mathrm{CM}$ and analyze the reason for choosing $\mathrm{CM}$ by surgeons.

\section{Methods}

A retrospective cohort study was conducted on all cesarean deliveries that were complicated with leiomyoma at two university hospitals from January 2010 to May 2020. This study obtained ethical approval from the Institutional Review Board of the Catholic University of Korea for the use of anonymized patient data for medical research (XC20WIDI0093). Data were collected from our electronic health record database and the data used in our research acquired administrative permissions. The study was conducted in accord with the guidelines of the Declaration of Helsinki, and the rights of all participants were protected. The study included women who were diagnosed with leiomyoma detected by antenatal ultrasound or with a history of a previous myomectomy (Fig. 1).

The maternal demographic characteristics included maternal age, body mass index (BMI), parity, gestational days at delivery, multiple pregnancies, fetal presentation, and neonatal birth weight, Apgar score of the neonates, fetal presentation, IUGR, and assisted reproduction techniques. The leiomyoma characteristics were evaluated and included the history of a previous uterine myomectomy and preterm labor. The leiomyomas were categorized by size, type, and number. The size of the leiomyomas was obtained from the pathology report. If there was no pathology report, the size or type of leiomyoma was obtained from the operative notes or antenatal ultrasound. 
We compared the outcomes of women who underwent CM to women who had a CS only without myomectomy. The measured outcome parameters included operation time, emergency operation, hemoglobin $(\mathrm{Hgb})$ changes between preoperative and postoperative values, transfusion after surgery, and intraoperative and postoperative complications such as postpartum hemorrhage, intrauterine balloon tamponade insertion, and hysterectomy.

The possible risk factors for adverse outcomes for women with $\mathrm{CM}$ were analyzed by multivariate regression analysis. The evaluated factors were related to the location of the leiomyoma, the number of leiomyomas, the size of the leiomyoma, neonatal birth weight, placenta problems, preeclampsia, and operation time $>60$ minutes.

\section{Statistical analysis}

All statistical analyses were conducted using SAS Version 9.4 (SAS Institute, Cary, NC, USA). The continuous data are presented as mean \pm standard deviation and the categorical data as number and percentage. P-values are calculated using the Chi-squared test or Fisher's exact test for categorical variables and the t-test or Wilcoxon rank-sum test for continuous variables. A P-value below 0.05 was considered statistically significant. To assess the independent predictors of adverse outcomes of CM, we calculated the odds ratios (ORs) and 95\% confidence intervals (Cls) using logistic regression models.

\section{Results}

From January 2010 to May 2020, 779 patients who underwent CS and were either diagnosed with leiomyoma $(n=548)$ or had a history of previous myomectomy $(n=231)$ were included. The average age of the patients in the CS only group was $34.8 \pm 3.6$ years and $34.8 \pm 3.7$ years in the CM group. There were 438 women in the CS-alone group and 341 women in the CM group (Table 1). 
Table 1

Epidemiologic characteristics between CS group and CM group.

\begin{tabular}{|c|c|c|c|}
\hline & CS group $(n=438)$ & CM group ( $n=341)$ & $P$ value \\
\hline Maternal age (years) & $34.8 \pm 3.6$ & $34.8 \pm 3.7$ & $0.918^{*}$ \\
\hline Height (cm) & $161.1 \pm 5.2$ & $161.6 \pm 5.2$ & $0.224^{*}$ \\
\hline Weight (kg) & $68.9 \pm 10$ & $69.4 \pm 11.1$ & $0.570^{*}$ \\
\hline BMI $\left(\mathrm{kg} / \mathrm{m}^{2}\right)$ & $26.3 \pm 3.4$ & $26.4 \pm 3.8$ & $0.758^{*}$ \\
\hline Nulliparous (\%) & $385(87.9)$ & $302(88.6)$ & 0.776 \\
\hline abortion, mean $\pm S D$ & $0.4 \pm 0.8$ & $0.4 \pm 0.8$ & 0.901 \\
\hline Gestational days at delivery (day) & $261.5 \pm 20$ & $259.2 \pm 21.7$ & 0.021 \\
\hline singlet/twin & & & 0.142 \\
\hline Single (\%) & $420(95.9)$ & $319(93.6)$ & \\
\hline Twin (\%) & $18(4.1)$ & $22(6.5)$ & \\
\hline Birth weight of baby (g) & $2891.7 \pm 685.8$ & $2818.4 \pm 734.4$ & 0.101 \\
\hline Apgar score at 5 minute $<7$ (\%) & $82(18.7)$ & $81(23.8)$ & 0.087 \\
\hline Presentation of fetus & & & 0.056 \\
\hline Cephalic (\%) & $374(85.8)$ & $281(82.4)$ & \\
\hline Abnormal presentation (\%) & $62(14.25)$ & $60(17.6 \%)$ & \\
\hline IUGR of baby (\%) & $38(8.7)$ & $36(10.6)$ & 0.374 \\
\hline Operation time (minute) & $44.5 \pm 18.2$ & $52.5 \pm 23.8$ & $<0.001$ \\
\hline Emergency operation (\%) & $133(30.4)$ & $110(32.3)$ & 0.572 \\
\hline \multicolumn{4}{|c|}{ Values are numbers(percentages) or means(SD) for categorical variables. } \\
\hline \multicolumn{4}{|c|}{$\begin{array}{l}P \text { values are calculated using Chi-square test or Fisher's exact test for categorical variables and t-test } \\
\text { or wilcoxon rank sum test for continuous variables }\end{array}$} \\
\hline \multicolumn{4}{|c|}{$\begin{array}{l}\text { CS cesarean section, } C M \text { cesarean myomectomy, BMI body mass index, IUGR intrauterine growth } \\
\text { retardation }\end{array}$} \\
\hline
\end{tabular}

The indications for CS included previous myomectomy $(n=209,26.8 \%)$, fetopelvic disproportion $(n=189$, $24.3 \%)$, fetal distress ( $n=77,9.9 \%$ ), abnormal fetal presentation (breech, transverse position, $n=77$, $9.9 \%)$, pathological placenta presentation (placenta previa, low-lying placenta, placental abruption) $(\mathrm{n}=$ 
$58,7.4 \%)$, known leiomyoma ( $n=63,8.1 \%)$, history of a previous cesarean section $(n=38,4.9 \%)$, IUGR, twins, preeclampsia, and preterm labor.

Table 1 shows the demographic characteristics of the study population. There were differences in the number of gestational days at delivery ( $261.5 \pm 20$ days (CS only group) vs $259.2 \pm 21.7$ days (CM group; $P=0.021)$ and the operation time (44.5 \pm 18.2 (CS only group) vs $52.5 \pm 23.8$ minutes (CM group); $P<$ 0.001 ) between the two groups. Although no statistically significant differences were detected between the groups in fetal presentation, the rate of abnormal presentations was slightly higher in the CM group $(17.6 \%$ vs $14.25 \% ; P=0.056)$. There were no significant differences in maternal age, maternal BMI, parity, number of fetuses, or emergency operations. Also, no significant differences were detected in terms of the Apgar scores of the neonates.

The characteristics related to uterine leiomyoma and operative outcomes are shown in Table 2. A lower percentage of patients in the $\mathrm{CM}$ group underwent a previous myomectomy ( $8.5 \%$ vs $46.1 \%$; $P<0.001)$, whereas there was a higher percentage of patients with a previous CS or preterm labor in the CM group ( $7.3 \%$ vs $3.4 \% ; P=0.014,32.3 \%$ vs $22.25 \% ; P=0.002$ ). The mean leiomyoma size in the $\mathrm{CM}$ group was $5.8 \pm 3.2 \mathrm{~cm}$ and it was significantly larger than that of the CS only group $(P=0.005)$. Also, the types of leiomyomas were different. Intramural leiomyoma was the most common in the CS only group (59.5\%), whereas subserosal leiomyoma was the most common in the CM group (48.7\%). More patients in the CM group $(90.9 \%)$ had fewer than three leiomyomas compared to the CS only group (72.4\%) who had a higher percentage of patients with multiple leiomyomas. The complications related to pregnancy, especially placenta problems, preeclampsia, and oligohydramnios, occurred significantly more often in the CS only group (24.4\%) than in the CM group (10.6\%). Pathologic examination revealed degeneration in $54.6 \%$ of the leiomyomas after $\mathrm{CM}$. One patient was later diagnosed with smooth uterine muscle of uncertain malignant potential and total hysterectomy was performed. There were no statistically significant differences in terms of postoperative complications such as postpartum hemorrhage, total hysterectomy, or the insertion of intrauterine balloon tamponade. 
Table 2

Characteristics related uterine leiomyoma between CS group and CM group related obstetrical factors

\begin{tabular}{|c|c|c|c|}
\hline & $\begin{array}{l}\text { CS } \\
\text { group } \\
(n=438)\end{array}$ & $\begin{array}{l}\text { CM } \\
\text { group } \\
(n=341)\end{array}$ & $P$ value \\
\hline History of previous CS (\%) & $15(3.4)$ & $25(7.3)$ & 0.014 \\
\hline History of previous myomectomy (\%) & $\begin{array}{l}202 \\
(46.1)\end{array}$ & $29(8.5)$ & $<0.001$ \\
\hline History of preterm labor (\%) & $\begin{array}{l}97 \\
(22.2)\end{array}$ & $\begin{array}{l}110 \\
(32.3)\end{array}$ & 0.002 \\
\hline Size of leiomyoma $(\mathrm{cm})$, mean $\pm S D$ & $5.2 \pm 3.1$ & $5.8 \pm 3.2$ & 0.005 \\
\hline Type of leiomyoma (\%) & & & $<0.001^{\dagger}$ \\
\hline Intramural leiomyoma & $\begin{array}{l}122 \\
(59.5)\end{array}$ & $\begin{array}{l}139 \\
(41.5)\end{array}$ & \\
\hline Subserosal leiomyoma & $\begin{array}{l}70 \\
(34.2)\end{array}$ & $\begin{array}{l}163 \\
(48.7)\end{array}$ & \\
\hline Submucosal leiomyoma & $4(2)$ & $5(1.5)$ & \\
\hline Mix type leiomyoma & $7(3.4)$ & $28(8.4)$ & \\
\hline Cervical leiomyoma & $2(1)$ & - & \\
\hline Number of leiomyoma (\%) & & & $<0.001$ \\
\hline Number $<3$ & $\begin{array}{l}165 \\
(72.4)\end{array}$ & $\begin{array}{l}301 \\
(90.9)\end{array}$ & \\
\hline Multiple & $\begin{array}{l}63 \\
(27.6)\end{array}$ & $30(9.1)$ & \\
\hline IVF (\%) & $\begin{array}{l}391 \\
(89.3)\end{array}$ & $\begin{array}{l}294 \\
(86.2)\end{array}$ & 0.195 \\
\hline Transfusion during CS (\%) & $22(5)$ & $16(4.7)$ & 0.832 \\
\hline $\begin{array}{l}\text { Complication of CS (PPH+Backri, adhesion, inverted C/sec, T/H) } \\
\text { (\%(\%) }\end{array}$ & $4(3.2)$ & $7(2.1)$ & 0.328 \\
\hline $\begin{array}{l}\text { Complication of pregnancy (Placenta problem(low lying, pl.previa, } \\
\text { pl.abruptio, pla.accreta),preeclampsia, oligohydramnios (\%) }\end{array}$ & $\begin{array}{l}107 \\
(24.4)\end{array}$ & 36 (10.6) & $<0.001$ \\
\hline \multicolumn{4}{|c|}{ Values are numbers(percentages) and means (standard deviation) for categorical variables. } \\
\hline \multicolumn{4}{|c|}{$P$ values are calculated using Chi-square test or Fisher's exact test $t$ for categorical variables. } \\
\hline $\begin{array}{l}\text { CS: cesarean section; CM: cesarean myomectomy; IVF: in vivo fer } \\
\text { hemorrhage; C/sec: cesarean section; } \mathrm{T} / \mathrm{H} \text { : total hysterectomy }\end{array}$ & ion; & postpart & \\
\hline
\end{tabular}


No significant difference between the groups in pre and postoperative hemoglobin levels was observed (Table 3). The initial preoperative Hgb was $12.1 \pm 1.3 \mathrm{mg} / \mathrm{dL}$ in the CS only group and $12 \pm 1.3 \mathrm{mg} / \mathrm{dL}$ in the CM group. The postoperative day $1 \mathrm{Hgb}$ in the CS only group was $11 \pm 1.4 \mathrm{mg} / \mathrm{dL}$ and $10.9 \pm 1.5$ $\mathrm{mg} / \mathrm{dL}$ in the $\mathrm{CM}$ group.

Table 3

Hematologic change between CS group and CM group

\begin{tabular}{|lccc|}
\hline & CS group & CM group & Pvalue \\
\hline Initial preop $\mathrm{Hb}(\mathrm{mg} / \mathrm{dL})$ & $12.1 \pm 1.3$ & $12 \pm 1.3$ & $0.313^{*}$ \\
\hline pod\# $1 \mathrm{Hb}(\mathrm{mg} / \mathrm{dL})$ & $11 \pm 1.4$ & $10.9 \pm 1.5$ & $0.761^{*}$ \\
\hline pod\#3Hb $(\mathrm{mg} / \mathrm{dL})$ & $10 \pm 1.3$ & $9.9 \pm 1.4$ & $0.311^{*}$ \\
\hline Values are means (standard deviation) for categorical variables. & \\
\hline $\begin{array}{l}P \text { values are calculated using Chi-square test or t-test } \\
\text { variables. }\end{array}$ & & \\
\hline CS or wilcoxon rank sum test for continuous \\
\hline
\end{tabular}

Multiple logistic regression analysis was performed to identify the risk factors for adverse outcomes after $\mathrm{CM}$ such as blood transfusion, a decrease in hemoglobin levels, or other postoperative complications. The size of the leiomyoma $(\mathrm{OR}=1.162 ; 95 \% \mathrm{Cl}: 1.07-1.25 ; P<0.001)$ and operation time $>60$ minutes $(\mathrm{OR}=2.461 ; 95 \% \mathrm{Cl}: 1.45-4.15 ; P=0.001)$ were significant independent predictors of adverse outcomes after CM (Table 4). 
Table 4

Independent risk factors of adverse outcomes of CM

\begin{tabular}{|llll|}
\hline & OR & $95 \%$ Cl & Pvalue \\
\hline Birth weight of baby & 1.000 & $1.000-1.000$ & 0.432 \\
\hline Size of leiomyoma & 1.162 & $1.077-1.253$ & $<0.001$ \\
\hline Number of leiomyoma $>3$ & 2.078 & $0.950-4.548$ & 0.067 \\
\hline Location of myoma (anterior) & 1.228 & $0.745-2.023$ & 0.42 \\
\hline Location of myoma (posterior) & 0.666 & $0.314-1.414$ & 0.29 \\
\hline placenta problem (low lying, pl.previa, pl.abruptio, pl.accreta) & 0.241 & $0.030-1.929$ & 0.18 \\
\hline preeclampsia & 0.891 & $0.273-2.910$ & 0.848 \\
\hline Operation time>60min & 2.461 & $1.458-4.154$ & 0.001 \\
\hline $\begin{array}{l}\text { Outcome: Transfusion or complication of CS or change of hematologic result(decrease of } \\
\text { Hgb>3mg/dL) }\end{array}$ & & & \\
\hline Odds ratios were calculated by using logistic regression. & & & \\
\hline OR odd ratio, $C /$ confidence interval & & & \\
\hline
\end{tabular}

\section{Discussion}

This study to evaluate the factors that determine complications during pregnancy associated with uterine leiomyoma provided important information for managing women's health. The incidence of uterine leiomyoma is continuously increasing, uterine surgery using robot including laparoscopic myomectomy has also increased. In particular, when uterine leiomyomas are present in young women of childbearing age or myomectomy has been performed, pregnancy-related problems and various complications may occur. Preterm labor, placental problems, and uterine rupture are particularly serious obstetrical problems, so research on pregnancy, uterine leiomyoma, and myomectomy is very important.

The mean gestational age at delivery was significantly lower in the CM group and this might have been due to the increased contractility of the myometrium with the presence and mass effect of the leiomyoma [9]. For similar reasons, the incidence of preterm labor was increased significantly in the CM group in our study. In addition, although not statistically significant, there was a higher rate of abnormal fetal presentations in the $\mathrm{CM}$ group, suggesting that the presence of leiomyomas affected fetal malpresentation $[10,11]$.

Our data suggested a significant difference $(8 \mathrm{~min})$ in the duration of surgery between the groups. In a previous report, the operation time was 4.94 minutes longer in the CM group than the CS-only group, 
which was not a significant difference [12]. In another study, the operation time in the CM group was 15 minutes longer than that of the CS-only group and this was a significant result [9].

The history of a previous myomectomy was significantly higher in the CS-only group than in the CM group. This may have been because the patients who underwent a previous myomectomy were likely to have fewer or no leiomyomas, so only a CS was performed. The history of a previous CS was significantly higher in the $\mathrm{CM}$ group. The probable reason for this was to prevent additional surgery due to remnant leiomyomas in the future.

Generally, CM has been controversial and is not recommended routinely. This is because CM tends to increase the rate of intraoperative or postoperative hemorrhage, and in the worst case, leads to hysterectomy, which surgeons fear, and pelvic adhesions due to bleeding. A meta-analysis was conducted in 2017 examining 19 studies and comparing a total of 2,301 patients who underwent CM with patients who underwent only CS [13]. This study reported that the group that underwent CM had a greater decrease in Hgb levels and needed more blood transfusions (mean difference in $\mathrm{Hgb} 0.25 \mathrm{mg} / \mathrm{dL}$, $95 \% \mathrm{Cl}: 0.06-0.45$; risk of transfusion OR: $1.41,95 \% \mathrm{Cl}: 0.96-2.07)$. In contrast, in a retrospective cohort study conducted in 2019, no differences were detected in terms of average $\mathrm{Hgb}$ decreases or blood transfusion rates between the patients who underwent CM and the patients who underwent only CS [14]. Similarly, in our study, we did not find any significant differences between the groups in hemoglobin level decreases or blood transfusion rates. In addition, postoperative complications such as the incidence of postpartum hemorrhage, postoperative insertion of intrauterine balloon tamponade, or hysterectomy also showed no significant differences. Therefore, $\mathrm{CM}$ is a reliable and safe approach, preventing the need for future operations.

Many factors should be carefully considered before performing CM such as the patient's condition, location of the leiomyoma, emergency status of the surgery, and the surgeon's skill. In particular, the surgeon's skill and preference for CM are likely to play an important role because CM can be associated with operative complications.

Pregnancy-related uterine rupture after myomectomy should be dangerous complication in mother and fetus. Gambacorti et al. reported that labor after myomectomy was associated with a $0.47 \%$ risk of uterine rupture [15]. According to a study by Koo et al., uterine rupture during pregnancy occurred in only three $(0.6 \%)$ cases out of 523 patients who underwent laparoscopic myomectomy [16]. This study concluded that laparoscopic myomectomy is a safe surgical option for women who desire pregnancy. However, studies on the correlation between $\mathrm{CM}$ and uterine rupture are very scarce. Additional research and investigation are required for a better understanding of the relationship.

Standardized indications for $\mathrm{CM}$ have not yet been defined. As can be derived from our results, the characteristics of leiomyomas in the CM group were mostly subserosal type, singular or fewer than three in number, or large in size. This seems to be a result of surgeons considering the risk-benefits of CM to avoid risk during surgery. According to a study by Zhao et al. [14], the presence of a leiomyoma larger than $5 \mathrm{~cm}$ and birth weight of more than $4,000 \mathrm{~g}$ were the important risk factors for postpartum 
hemorrhage of $\geq 1,000 \mathrm{ml}$ in pregnant women with leiomyomas during CS, whereas the location and type of leiomyoma had little effect. Kwon et al. reported that large size exceeding $8 \mathrm{~cm}$ and lower segmental position of the leiomyoma were significant risk factors for intraoperative hemorrhage during CM [17].

\section{Conclusions}

$\mathrm{CM}$ is a considerable safe approach in pregnant women with leiomyoma. In the present study, the independent risk factors affecting adverse outcomes after $\mathrm{CM}$ were the size of the leiomyoma and the duration of surgery. The larger the leiomyoma and the longer the surgery, the higher the risk of adverse outcomes. A prospective study on the effectiveness of $\mathrm{CM}$ is needed. It seems that objective data on the surgeon's skill and safety of CM should be accumulated. Therefore, novel guidelines for CM may be developed from future studies.

\section{Abbreviations}

BMI

body mass index

$\mathrm{Cl}$

confidence interval

$\mathrm{CM}$

cesarean myomectomy

CS

cesarean section

$\mathrm{Hgb}$

Hemoglobin

IUGR

intrauterine growth retardation

OR

odds ratio

\section{Declarations}

\section{Ethics approval and consent to participate}

This study obtained ethical approval from the Institutional Review Board of the Catholic University of Korea for the use of anonymized patient data for medical research. . The study was conducted in accord with the guidelines of the Declaration of Helsinki, and the rights of all participants were protected. The need for an informed consent was waived by the IRB listed above because this was a retrospective cohort study.

\section{Consent for publication}


Not applicable since there are no details, images, or videos relating to an individual person.

\section{Availability of data and materials}

All authors had full access to the data and materials. Data is available from the authors upon reasonable request.

\section{Competing interests}

The authors declare that they have no competing interests.

\section{Funding}

This work was supported by the Institute of Clinical Medicine Research of Bucheon St. Mary's Hospital, Research Fund, 2020.

This study was supported by the Research Fund of Seoul St. Mary's Hospital, The Catholic University of Korea.

\section{Authors' contributions}

$\mathrm{MJ}$ designed the study. $\mathrm{MJ}, \mathrm{JH}$ and $\mathrm{IY}$ extracted and analyzed data. $\mathrm{KE}$ and $\mathrm{JH}$ conducted the literature search. $\mathrm{MJ}$ and $\mathrm{JH}$ wrote the first draft of the manuscript. IY contributed to the discussion and drafting of the manuscript. All authors reviewed and approved the final version of the manuscript prior to submission.

\section{Acknowledgments}

Statistical consultation was provided by the Department of Biostatistics of the Catholic Research Coordinating Center.

\section{References}

1. Practice Committee of American Society for Reproductive Medicine in collaboration with Society of Reproductive Surgeons. Myomas and reproductive function. Fertil Steril. 2008;90(5 Suppl):S125-30.

2. Health Insurance Review \& Assessment Service. Healthcare Bigdata Hub. 2021. http://opendata.hira.or.kr/op/opc/olapMfrnIntrsllnsInfo.do. Accessed 21 Oct 2021.

3. Ciavattini A, Clemente N, Delli Carpini G, Di Giuseppe J, Giannubilo SR, Tranquilli AL. Number and size of uterine fibroids and obstetric outcomes. J Matern Fetal Neonatal Med. 2015;28(4):484-8.

4. Dedes I, Schäffer L, Zimmermann R, Burkhardt T, Haslinger C. Outcome and risk factors of cesarean delivery with and without cesarean myomectomy in women with uterine myomatas. Arch Gynecol Obstet. 2017;295(1):27-32. 
5. El-Refaie W, Hassan M, Abdelhafez MS. Myomectomy during cesarean section: A retrospective cohort study. J Gynecol Obstet Hum Reprod. 2020:101900.

6. Patel S, Patel S, Roberts S, Rogers V, Zink A, Duryea E, et al. Williams Obstetrics. 25th ed. New York: McGraw-Hill; 2018.

7. Kumar RR, Patil M, Sa S. The utility of caesarean myomectomy as a safe procedure: a retrospective analysis of 21 cases with review of literature. J Clin Diagn Res. 2014;8(9):0c05-8.

8. Huang Y, Ming X, Li Z. Feasibility and safety of performing cesarean myomectomy: a systematic review and meta-analysis. J Matern Fetal Neonatal Med. 2020:1-9.

9. Sakinci M, Turan G, Sanhal CY, Yildiz Y, Hamidova A, Guner FC, et al. Analysis of Myomectomy during Cesarean Section: A Tertiary Center Experience. J Invest Surg. 2020:1-7.

10. Klatsky PC, Tran ND, Caughey AB, Fujimoto VY. Fibroids and reproductive outcomes: a systematic literature review from conception to delivery. Am J Obstet Gynecol. 2008;198(4):357-66.

11. Parazzini F, Tozzi L, Bianchi S. Pregnancy outcome and uterine fibroids. Best Pract Res Clin Obstet Gynaecol. 2016;34:74-84.

12. Krishnakumar S, Tambe PS. Laparoscopic Myomectomy. In: Palshetkar N, Pai RD, Tambe P, Kale D, Palshetkar R, editors. Smart Obstetrics \& Gynecology Handbook. New Delhi: The Health Sciences Publisher; 2016.

13. Pergialiotis V, Sinanidis I, Louloudis IE, Vichos T, Perrea DN, Doumouchtsis SK. Perioperative Complications of Cesarean Delivery Myomectomy: A Meta-analysis. Obstet Gynecol. 2017;130(6):1295-303.

14. Zhao R, Wang X, Zou L, Zhang W. Outcomes of Myomectomy at the Time of Cesarean Section among Pregnant Women with Uterine Fibroids: A Retrospective Cohort Study. Biomed Res Int. 2019;2019:7576934.

15. Gambacorti-Passerini Z, Gimovsky AC, Locatelli A, Berghella V. Trial of labor after myomectomy and uterine rupture: a systematic review. Acta Obstet Gynecol Scand. 2016;95(7):724-34.

16. Koo YJ, Lee JK, Lee YK, Kwak DW, Lee IH, Lim KT, et al. Pregnancy Outcomes and Risk Factors for Uterine Rupture After Laparoscopic Myomectomy: A Single-Center Experience and Literature Review. J Minim Invasive Gynecol. 2015;22(6):1022-8.

17. Kwon JY, Byun JH, Shin I, Hong S, Kim R, Park IY. Risk factors for intraoperative hemorrhage during cesarean myomectomy. Taiwan J Obstet Gynecol. 2021;60(1):41-4.

\section{Figures}




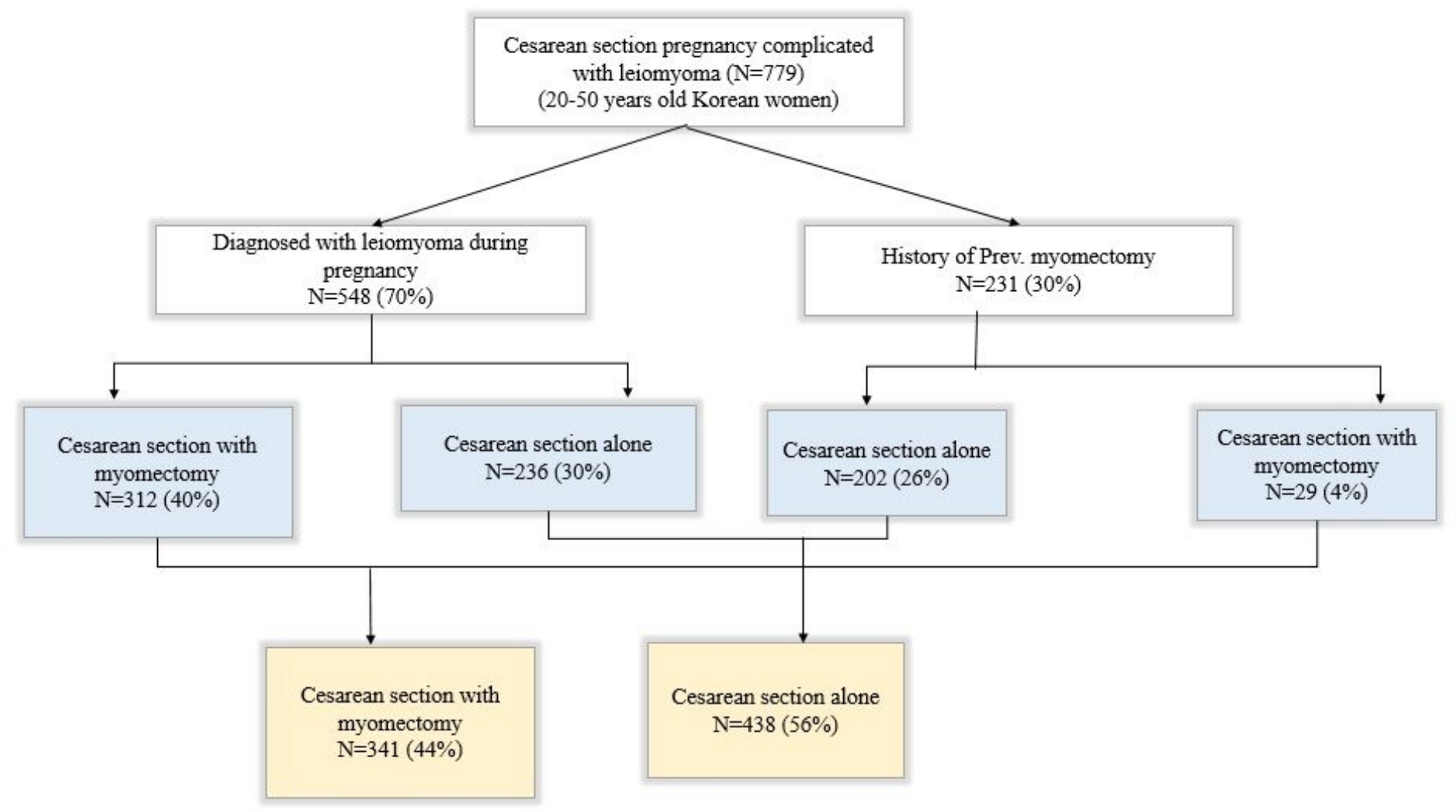

\section{Figure 1}

Flow chart for selection of studies. 